BMJ Open

Respiratory

Research

\title{
A study of patients with isolated mediastinal and hilar lymphadenopathy undergoing EBUS-TBNA
}

\author{
Matthew Evison, ${ }^{1,2}$ Philip A J Crosbie, ${ }^{1,2}$ Julie Morris, ${ }^{3}$ Julie Martin, ${ }^{1}$ \\ Philip V Barber, ${ }^{1}$ Richard Booton ${ }^{1,2}$
}

To cite: Evison M,

Crosbie PAJ, Morris J, et al. A study of patients with isolated mediastinal and hilar lymphadenopathy undergoing EBUS-TBNA. BMJ Open Resp Res 2014;1:e000040. doi:10.1136/bmjresp-2014000040

Received 7 April 2014 Revised 14 May 2014 Accepted 15 May 2014

\section{(1) CrossMark}

${ }^{1}$ North West Lung Centre, University Hospital of South Manchester, Manchester, UK ${ }^{2}$ The Institute of Inflammation and Repair, The University of Manchester, Manchester, UK

${ }^{3}$ Department of Medical Statistics, University Hospital of South Manchester, Manchester, UK

Correspondence to Dr Matthew Evison; matthew.evison@hotmail.co.uk

\section{ABSTRACT}

Background: Isolated mediastinal and/or hilar lymphadenopathy (IMHL) may be caused by benign and malignant disorders or be 'reactive'. Endobronchial ultrasound-guided transbronchial needle aspiration (EBUS-TBNA) has a reported low negative predictive value (NPV) in IMHL, necessitating mediastinoscopy in selected patients. The aim of this study was to examine the NPV of EBUS-TBNA in an IMHL population and determine whether clinical variables differentiate between pathological and reactive IMHL.

Methods: Analysis of a prospectively maintained database of consecutive patients with IMHL referred to a single UK centre for EBUS-TBNA.

Results: 100 patients with IMHL had EBUS-TBNA during the study (March 2010-February 2013), mean age $58.6 \pm 15.7$ years, $63 \%$ men, $70 \%$ white British and mean follow-up $16.8 \pm 8.6$ months. Pathological cause of IMHL established in 52 patients (sarcoidosis $\mathrm{n}=20$, tuberculosis $n=18$, carcinoma $n=7$, lymphoma $n=6$, benign cyst $n=1$ ), 43 from EBUS-TBNA. 48/57 negative EBUS-TBNA samples were true negatives reflecting reactive lymphadenopathy in $48 \%$. The diagnostic accuracy of EBUS-TBNA was $91 \%$ and NPV was $84.2 \%$ (95\% Cl $72.6 \%$ to $91.5 \%)$. Multivariate analysis of clinical covariates showed age (odds ratio (OR) 1.07, $95 \% \mathrm{Cl} 1.01$ to $1.13 ; p=0.033$ ), the presence of a relevant comorbidity (OR $9.49,95 \% \mathrm{Cl} 2.20$ to 41.04 ; $\mathrm{p}=0.003$ ) and maximum lymph node size (OR 0.70 , $95 \% \mathrm{Cl} 0.59$ to $0.83 ; \mathrm{p}=0.00004$ ) to differentiate between reactive and pathological IMHL. Stratification of the study population according to comorbidity and maximum lymph node size $(<20 \mathrm{~mm})$ identified a lowrisk cohort $(\mathrm{n}=32)$ where the NPV of EBUS-TBNA was $93.8 \%$ (95\% Cl $79.9 \%$ to $98.3 \%$ ).

Conclusions: Reactive lymphadenopathy accounts for a significant proportion of patients with IMHL. In carefully selected patients with IMHL and a negative EBUS-TBNA, surveillance rather than further invasive sampling may be an appropriate strategy.

\section{INTRODUCTION}

Isolated mediastinal and/or hilar lymphadenopathy (IMHL) is a relatively common reason for respiratory physician referral in the UK. The differential diagnosis includes

\section{KEY MESSAGES}

The cause of IMHL was reactive lymphadenopathy in $48 \%$ of cases in this study. This is a significantly higher proportion than in previous studies of IMHL. We postulate this is due to the increasing prevalence of chronic diseases associated with reactive lymphadenopathy, eg, emphysema and heart failure, and the ever increasing use of computed tomography.

- The negative predictive value of EBUS-TBNA is also significantly higher in this study $(84.2 \%)$ compared to previous studies of this specific patient group and is related to the prevalence of reactive lymphadenopathy.

- In those patients with a co-morbidity known to be associated with IMHL and a largest lymph node size of less than $20 \mathrm{~mm}$ in short axis, the NPV of EBUS-TBNA was $93.8 \%$.

benign granulomatous disorders, for example, tuberculosis (TB) and sarcoidosis, ${ }^{1}$ and malignancy, including lymphoma and metastatic carcinoma. Rarer causes include lymphoproliferative disorders, for example, Castleman's disease, ${ }^{2}$ primary hypogammaglobulinaemia ${ }^{3}$ and histoplasmosis. ${ }^{4}$ Lymph nodes may also enlarge as a reaction to underlying comorbidities, when a designation of 'reactive' lymphadenopathy may be made. Reactive lymphadenopathy has been associated with a number of chronic conditions, including emphysema and chronic bronchitis, ${ }^{5}{ }^{6}$ interstitial lung disease, ${ }^{7} 8$ bronchiectasis, ${ }^{9}$ pulmonary arterial hypertension, ${ }^{10}$ heart failure ${ }^{11-16}$ and connective tissue disease. ${ }^{17}$ Mediastinal lymph node enlargement has been reported to be present in half of the patients with chronic obstructive pulmonary disease in one series, irrespective of the degree of airflow obstruction, ${ }^{6}$ and between $35 \%$ and $66 \%$ in patients with severe chronic cardiac failure, ${ }^{11-13} 1516$ where lymphadenopathy may be secondary 
to raised left atrial filling pressures resulting in increased lymphatic fluid. ${ }^{12} 18-20$

Pathological/microbiological confirmation is recommended in patients with IMHL to ensure appropriate treatment. ${ }^{21}$ Endobronchial ultrasound-guided transbronchial needle aspiration (EBUS-TBNA) has been shown to be highly effective in the diagnosis of granulomatous IMHL and nodal staging in lung cancer. ${ }^{22-26}$ The sensitivity for lymphoma is lower as larger tissue samples are often required. ${ }^{27}$ The REMEDY trial, ${ }^{21}$ the only prospective study of EBUS-TBNA in patients with IMHL requiring pathological confirmation, demonstrated high sensitivity (92\%) and cost-effectiveness of EBUS-TBNA as a firstline investigation, preventing mediastinoscopy in $87 \%$ of patients. However, of 10 patients $(10 / 77,13 \%)$ with a negative EBUS-TBNA, 6 were false negatives, giving a negative predictive value (NPV) of $40 \%$. The authors therefore recommended mediastinoscopy in cases of negative EBUS-TBNA sampling. Of note, however, was the low prevalence of reactive lymphadenopathy $(5 \%)$ in this study, possibly reflecting the highly selected nature of the population.

The aims of our study were to investigate the causes of IMHL in patients referred to our centre for EBUS-TBNA and determine the diagnostic performance, in particular the NPV, of EBUS-TBNA in this population. In addition, we wanted to prospectively explore clinically measurable variables that could be used to differentiate the reactive from the pathological causes of IMHL.

\section{MATERIALS AND METHODS}

This study was an analysis of a prospectively maintained database of all patients referred to the University Hospital of South Manchester (UHSM) with IMHL for EBUS-TBNA from March 2010 to February 2013. UHSM provides an EBUS service for a large network of National Health Service (NHS) trusts in the North West of England. The decision to refer patients with IMHL for EBUS-TBNA was at the discretion of the primary physician. IMHL was defined as the presence of at least one enlarged mediastinal or hilar lymph node on CT ( $>10 \mathrm{~mm}$ in short axis) without an intraparenchymal nodule or mass and without evidence of extrathoracic malignancy.

Clinical covariates prospectively recorded included patient demographics; symptoms at presentation (defined as asymptomatic or symptomatic if any of the following were present: cough, dyspnoea, chest pain, weight loss, fevers or night sweats); the presence or absence of comorbidity with published evidence of an association with IMHL: emphysema (moderate to severe on CT), chronic bronchitis (bronchial wall thickening on CT in a current or former smoker), interstitial lung disease, bronchiectasis (combination of bronchial wall thickening and bronchial dilation greater than the adjacent blood vessel), pulmonary arterial hypertension (echocardiogram finding or dilation of the pulmonary artery greater than the adjacent ascending aorta), heart failure (any condition leading to pulmonary venous hypertension including mitral valve disease and left ventricular systolic dysfunction) and connective tissue disorders. Lymph node variables included total number of enlarged lymph node stations, pattern of lymph node enlargement (mediastinal/hilar or both, unilateral vs bilateral) and largest lymph node size $(\mathrm{mm})$. Lymph node stations were classified according to the International Association for the Study of Lung Cancer Lymph Node Staging Map. ${ }^{28}$

Standard diagnostic bronchoscopy (Olympus BFF260 or BF6C260 bronchoscopes) was performed immediately prior to EBUS (Olympus BF-UC260FW ultrasonic bronchoscope) with incremental doses of alfentanil and midazolam used for conscious sedation. Targeted procedures were performed whereby enlarged lymph node stations, identified on preprocedure CT, were directly inspected and sampled sequentially. A minimum of one EBUS-TBNA sample was sent for mycobacterial culture for every patient and at least two samples per lymph node in cases with a high pretest probability of TB. All other samples were sent for cytological analysis but rapid on-site evaluation is not available. All procedures were performed by two of four operators (two respiratory consultants, one nurse consultant bronchoscopist and an interventional bronchoscopy fellow). Additional samples were taken at the discretion of the primary operator including random endobronchial biopsies if sarcoidosis was suspected. Complications were recorded by the primary operator and are classified according to national bronchoscopy guidelines. ${ }^{29}$

Prospective data collection ended in February 2013. Six months later (September 2013), all cases were reviewed and the following outcomes recorded: the pathological results of EBUS-TBNA (as well as any other bronchoscopic samples taken during the procedure), the pathological results of any subsequent relevant sampling and the outcome of clinical-radiological follow-up up to September 2013. This enabled a minimum of 6 months follow-up for all patients but a much longer period of surveillance in the majority of cases. The decision to undertake further sampling was at the discretion of the referring physician and not mandated by the EBUS centre. Based on the EBUS-TBNA results, subsequent sampling results and the outcome of clinicalradiological follow-up, a final diagnosis of sarcoidosis, $\mathrm{TB}$, lymphoma, carcinoma or reactive lymphadenopathy was made. A diagnosis of reactive lymphadenopathy was made only if all pathological sampling and a minimum of 6 months follow-up failed to yield an alternative diagnosis, and the referring physician did not consider the patient as having an alternative diagnosis. For example, if a referring physician considered a patient to have sarcoidosis despite negative pathological sampling and stability or regression of lymphadenopathy radiologically, this was considered a false negative. 


\section{Statistical analysis}

Diagnostic performance of EBUS-TBNA was calculated based on standard criteria. The 95\% CI for the NPV was calculated using the Wilson method. Analysis was stratified according to the final diagnosis and statistically significant differences determined using $\chi^{2}$ or Fisher's exact tests; a $p$ value of 0.05 or less was considered significant. Patients were categorised according to reactive or pathological (sarcoidosis, TB, carcinoma, lymphoma) causes of IMHL and univariate analysis performed using predefined clinical and lymph node covariates. Factors with a $\mathrm{p}$ value $<0.1$ were taken forward to be included in a multivariate analysis to determine variables that differed significantly between reactive and pathological causes of IMHL. Only factors with $\mathrm{p}$ values $\leq 0.05$ were retained for the final model. The model was checked using forward and reverse conditional data entry to ensure stability of the outcome.

\section{RESULTS}

A total of 100 patients underwent EBUS-TBNA for IMHL during the study period. The mean age was 58.6 \pm 15.7 years, 63 were men and 70 of white British ethnicity (table 1). A minimum of 6 months clinical-radiological follow-up was successfully achieved in 99 patients; 1 patient with small cell lung cancer died prior to the completion of 6 months follow-up. The mean follow-up duration was $16.8 \pm 8.6$ months. There was one major complication: an unplanned admission with postbronchoscopy fever.

\section{Causes of IMHL and performance characteristics of EBUS-TBNA}

EBUS-TBNA provided a positive diagnosis in 43 patients, and 57 patients had a negative EBUS-TBNA. Positive diagnoses included 33 patients with granulomatous disorders (TB $n=17$, sarcoidosis $n=16$ ), 9 patients with malignancy (carcinoma $n=7$, lymphoma $n=2$ ) and 1 patient with a mediastinal cyst. From the 57 patients with negative EBUS-TBNA sampling, 10 underwent further relevant pathological sampling as well as clinical-radiological follow-up (mediastinoscopy $n=7$, repeat EBUS $n=2$ and supraclavicular lymph node biopsy $n=1$ ) and 47 underwent clinical-radiological follow-up alone. From these 57 patients, 9 were subsequently diagnosed with a pathological cause of IMHL (sarcoidosis $n=4$, lymphoma $n=4$ and $T B n=1$ ) and the EBUS-TBNA categorised as false negative. The remainder were categorised as true negatives after completing the follow-up period and labelled as reactive lymphadenopathy $(n=48$; figure 1). In eight patients, the lymphadenopathy resolved entirely on serial imaging. The final diagnosis was reactive in 48 patients, a granulomatous disorder in 38 (sarcoidosis $n=20, T B n=18$ ), malignancy in 13 (carcinoma $n=7$, lymphoma $n=6$ ) and a mediastinal cyst in 1. All carcinomas were primarily lung in origin. EBUS-TBNA correctly diagnosed $16 / 20$ patients with sarcoidosis, $17 / 18$ patients with $\mathrm{TB}, 2 / 6$ patients with lymphoma and $7 / 7$ patients with carcinoma (table 1 ). The overall NPV for EBUS-TBNA in this cohort was $84.2 \%$ (95\% CI $72.6 \%$ to $91.5 \%$ ) and the diagnostic accuracy $91 \%$.

\section{Patient characteristics and final diagnosis \\ Age and sex}

The mean age of patients diagnosed with reactive lymphadenopathy was $66.0 \pm 11.1$ years, significantly older than patients with granulomatous disorders (46.1 \pm 14.2 years; $\mathrm{p}<0.000001$ ) but of a similar age to patients with malignancy (68.8 \pm 9.6 years; $\mathrm{p}=0.41$; figure 2$)$. Sex did not differ according to diagnosis.

\section{Ethnicity}

The prevalence of reactive lymphadenopathy differed significantly according to ethnicity; $60 \%$ of IMHL was reactive in white British $(\mathrm{n}=42 / 70)$ and $23.3 \%(\mathrm{n}=7 / 30)$ in Asian/African patients $(\mathrm{p}=0.001)$. All pathological diagnoses were secondary to granulomatous disorders in the Asian/African population representing a much higher proportion than white British patients $(n=23 / 30$, $76.7 \%$ vs $\mathrm{n}=15 / 70,21.4 \%$; $\mathrm{p}=0.0001$ ); all patients diagnosed with TB $(n=18)$ were of Asian/African ethnicity.

\section{Symptoms at presentation}

Asymptomatic presentation of IMHL was an uncommon occurrence $(n=13)$. The frequency of asymptomatic presentation was highest in patients with sarcoidosis $(n=5 / 20)$ but was low in all other groups. The presence of symptoms was similar between patients with reactive and pathological causes of IMHL $(p=0.46)$. The most common symptom in patients with reactive IMHL was cough and breathlessness reflective of the comorbidities present in these patients. Weight loss was commonly reported in patients with malignancy $(n=11 / 13)$ and TB $(n=10 / 18)$ but rarely in patients with sarcoidosis $(n=1 / 20)$ and reactive IMHL $(n=5 / 48)$. Fever was reported by half of the patients with a diagnosis of TB $(n=10 / 18)$ and lymphoma $(n=3 / 6)$ but rarely in other groups.

\section{Comorbidity}

Overall, 46 patients had at least one comorbidity associated with IMHL (table 1). Significantly more patients had a comorbidity in the reactive $(n=39 / 48,81.2 \%)$ than pathological IMHL group $(\mathrm{n}=7 / 52,13.5 \%$; $\mathrm{p}<0.000001)$. Of the pathological diagnoses, carcinoma had the highest proportion of patients with a comorbidity $(n=3 / 7,43 \%)$, with comorbidities being rare in other groups. Chronic bronchitis, emphysema and heart failure were the most common of these comorbidities (figure 3).

\section{Lymph node characteristics and final diagnosis Number of enlarged lymph node stations}

The number of enlarged lymph node stations across the study was $\leq 2$ stations $n=38 ; 3-4$ stations $n=40 ; \geq 5$ stations 
Table 1 Patient characteristics (including symptoms at presentation and comorbidity), lymph node measurements and procedure sensitivity overall categorised according to final diagnosis*

\begin{tabular}{|c|c|c|c|c|c|c|c|}
\hline \multicolumn{2}{|l|}{ Characteristic } & \multirow{2}{*}{$\begin{array}{l}\text { All } \\
100\end{array}$} & \multirow{2}{*}{$\begin{array}{l}\text { Reactive } \\
\text { LN } \\
48\end{array}$} & \multirow{2}{*}{$\begin{array}{l}\text { Sarcoidosis } \\
20\end{array}$} & \multirow{2}{*}{$\begin{array}{l}\text { Tuberculosis } \\
18\end{array}$} & \multirow{2}{*}{$\begin{array}{l}\text { Carcinoma } \\
7\end{array}$} & \multirow{2}{*}{$\begin{array}{l}\text { Lymphoma } \\
6\end{array}$} \\
\hline Total & Number & & & & & & \\
\hline Age & Mean years $\pm S D$ & $58.6 \pm 15.7$ & $66.0 \pm 11.1$ & $50.6 \pm 13.8$ & $41.2 \pm 13.3$ & $70.9 \pm 5.3$ & $66.3 \pm 13.2$ \\
\hline Sex & M/F (male, \%) & $63 / 37$ & $34 / 14(71)$ & $12 / 8(60)$ & 10/8 (56) & $3 / 4(43)$ & $4 / 2(67)$ \\
\hline \multirow[t]{3}{*}{ Ethnicity } & White British (\%) & 70 & $41(85)$ & $15(75)$ & $0(0)$ & $7(100)$ & $6(100)$ \\
\hline & Asian (\%) & 24 & $5(11)$ & $3(15)$ & $16(89)$ & $0(0)$ & $0(0)$ \\
\hline & African (\%) & 6 & $2(4)$ & $2(10)$ & $2(11)$ & $0(0)$ & $0(0)$ \\
\hline Symptomatic & Y/N (\%, yes) & 87 & $43(90)$ & $15(75)$ & $15(83)$ & 7 (100) & $6(100)$ \\
\hline $\begin{array}{l}\text { Number of } \\
\text { symptoms }\end{array}$ & Mean $\pm S D$ & $1.8 \pm 1.0$ & $1.7 \pm 0.9$ & $1.2 \pm 0.8$ & $2.3 \pm 1.1$ & $2.3 \pm 1.1$ & $2.7 \pm 0.8$ \\
\hline \multirow{6}{*}{$\begin{array}{l}\text { Presence of } \\
\text { symptom } \\
\text { Yes (\%) }\end{array}$} & Cough & 65 & 33 (69) & $9(45)$ & $15(83)$ & $3(43)$ & $4(67)$ \\
\hline & Breathlessness & 52 & $35(73)$ & 7 (35) & $4(22)$ & $5(71)$ & 1 (17) \\
\hline & Weight loss & 27 & $5(10)$ & $1(5)$ & $10(56)$ & $6(86)$ & $5(83)$ \\
\hline & Fevers & 18 & $2(4)$ & $3(15)$ & $10(56)$ & 0 & $3(50)$ \\
\hline & Chest pain & 9 & $3(6)$ & $1(5)$ & $2(11)$ & $1(14)$ & $1(17)$ \\
\hline & Other & 9 & $4(8)$ & $2(10)$ & 0 & $1(14)$ & 2 (33) \\
\hline \multirow{8}{*}{$\begin{array}{l}\text { Presence of } \\
\text { comorbidity } \\
\text { Yes (\%) }\end{array}$} & $\geq 1$ Comorbidity & 46 & $39(81)$ & $2(10)$ & $1(6)$ & $3(43)$ & $1(17)$ \\
\hline & Emphysema & 18 & $13(27)$ & $2(10)$ & 0 & $3(43)$ & 0 \\
\hline & $\begin{array}{l}\text { Chronic } \\
\text { bronchitis }\end{array}$ & 22 & $20(42)$ & $1(5)$ & $1(6)$ & 0 & 0 \\
\hline & ILD & 5 & $4(8)$ & 0 & 0 & $1(14)$ & 0 \\
\hline & Bronchiectasis & 10 & $8(17)$ & 0 & 0 & $1(14)$ & $1(17)$ \\
\hline & Pulmonary HT & 8 & $8(17)$ & 0 & 0 & 0 & 0 \\
\hline & Heart failure & 13 & $13(27)$ & 0 & 0 & 0 & 0 \\
\hline & CTD & 2 & $1(30)$ & 0 & 0 & $1(14)$ & 0 \\
\hline \multirow{5}{*}{$\begin{array}{l}\text { Diameter of largest } \\
\text { LN } \\
\text { Site of LN } \\
\text { enlargement }\end{array}$} & Mean $(m m \pm S D)$ & $21.8 \pm 7.2$ & $17.0 \pm 3.9$ & $24.2 \pm 4.0$ & $24.1 \pm 6.6$ & $28.3 \pm 4.9$ & $33.5 \pm 7.3$ \\
\hline & Range (mm) & $11-46$ & $11-25$ & $16-32$ & $16-40$ & $21-35$ & $24-46$ \\
\hline & Hilar only (\%) & 7 & $4(8)$ & 0 & $2(11)$ & 0 & $1(17)$ \\
\hline & $\begin{array}{l}\text { Mediastinal only } \\
(\%)\end{array}$ & 35 & $16(33)$ & 0 & $12(67)$ & $4(57)$ & $2(33)$ \\
\hline & Both (\%) & 58 & $28(58)$ & 20 (100) & $4(22)$ & $3(43)$ & $3(50)$ \\
\hline Number of enlarged & $1-2(\%)$ & 38 & $19(40)$ & 0 & $13(72)$ & $4(57)$ & 2 (33) \\
\hline \multirow{3}{*}{ LN stations } & $3-4(\%)$ & 40 & $25(52)$ & $5(25)$ & $4(22)$ & $3(43)$ & 2 (33) \\
\hline & $\geq 5(\%)$ & 22 & $4(8)$ & $15(75)$ & $1(5)$ & 0 & $2(33)$ \\
\hline & mean $\pm S D$ & $3.1 \pm 1.3$ & $2.8 \pm 1.1$ & $4.8 \pm 0.6$ & $2.3 \pm 1.1$ & $2.3 \pm 1.1$ & $3.2 \pm 1.6$ \\
\hline $\begin{array}{l}\text { EBUS-TBNA } \\
\text { sensitivity }\end{array}$ & Per cent & 82.7 & - & 80 & 94.4 & 100 & 33.3 \\
\hline
\end{tabular}

*Mediastinal cyst $(n=1)$ not listed as a cause in the table-but is included in the analysis.

CTD, connective tissue disease; EBUS-TBNA, Endobronchial ultrasound-guided transbronchial needle aspiration; ILD, interstitial lung disease; HT, hypertension; LN, lymph node.

$\mathrm{n}=22$ (table 1 and figure 4). The mean number of lymph node stations enlarged was higher for patients with pathological than reactive IMHL $(3.4 \pm 1.5$ vs $2.8 \pm 1.1$; $\mathrm{p}=0.04$ ). This difference was mainly due to patients with sarcoidosis; $75 \%$ had $\geq 5$ enlarged stations. Patients with TB $(\mathrm{n}=1 / 18,5.6 \%)$, carcinoma $(\mathrm{n}=0 / 7)$ and reactive lymphadenopathy $(n=4 / 48,8.3 \%)$ only rarely had five or more enlarged lymph node stations (table 1).

\section{Pattern of lymph node enlargement}

The most common patterns of lymphadenopathy were unilateral mediastinal lymphadenopathy $(30 \%)$, unilateral mediastinal and unilateral hilar lymphadenopathy (22\%) and bilateral mediastinal and hilar lymphadenopathy $(21 \%)$. Only $7 \%$ had hilar lymphadenopathy alone.
Seventy-five per cent $(15 / 20)$ of patients with sarcoidosis had bilateral mediastinal and hilar lymphadenopathy. Sixty-seven per cent $(12 / 18)$ of patients with TB had unilateral mediastinal lymphadenopathy. Fifty-eight per cent $(28 / 48)$ of patients with reactive lymphadenopathy had either unilateral mediastinal lymphadenopathy or unilateral mediastinal and hilar lymphadenopathy.

\section{Maximum lymph node size}

The mean size of the largest lymph node (short axis diameter) across the study group was $21.8 \pm 7.2 \mathrm{~mm}$; the lymph node diameter was significantly smaller in patients with reactive lymphadenopathy $(\mathrm{n}=48,17.0$ $\pm 3.9 \mathrm{~mm}$ ) compared with patients with a pathological diagnosis $(\mathrm{n}=52,26.2 \pm 6.7 \mathrm{~mm} ; \mathrm{p}<0.000001$; figure 5 


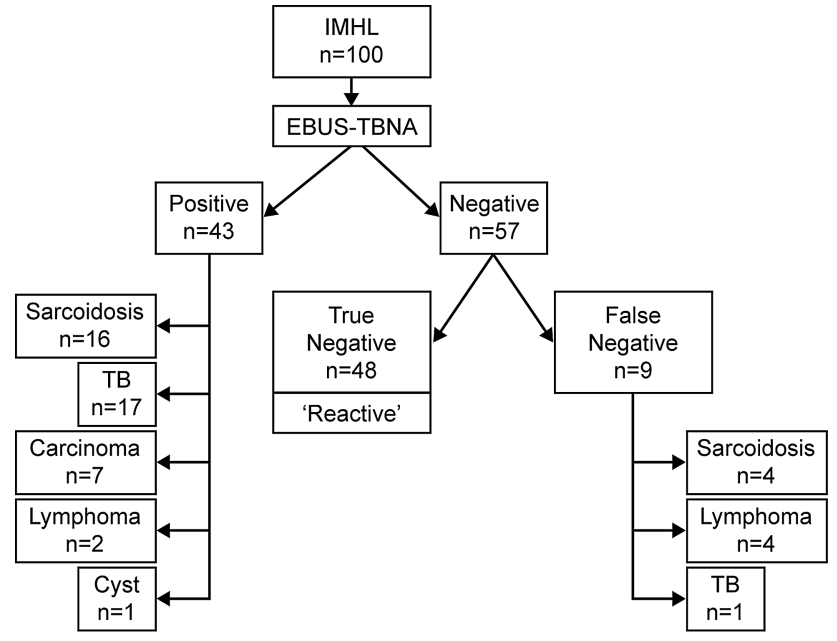

Figure 1 Diagrammatic representation of diagnostic performance characteristics of endobronchial ultrasound-guided transbronchial needle aspiration (EBUS-TBNA) in an isolated mediastinal and/or hilar lymphadenopathy (IMHL) population.

and table 1). The largest size was seen in lymphoma (mean diameter $33.5 \pm 7.3 \mathrm{~mm}$, range $24-46 \mathrm{~mm}$ ). All patients with a maximum lymph node diameter of $15 \mathrm{~mm}$ or less had a final diagnosis or reactive IMHL $(\mathrm{n}=19)$. Lymph nodes of $20 \mathrm{~mm}$ or less in diameter were significantly more likely to be reactive in nature $(n=38 /$ $46,82.6 \%$ ) compared with lymph nodes greater than this size $(n=10 / 54,18.5 \% ; p<0.000001)$.

\section{Differentiating reactive and pathological IMHL}

A univariate and multivariate analysis was undertaken to determine factors that differed significantly between patients with reactive and pathological IMHL (table 2). In univariate analysis, factors associated with an increased

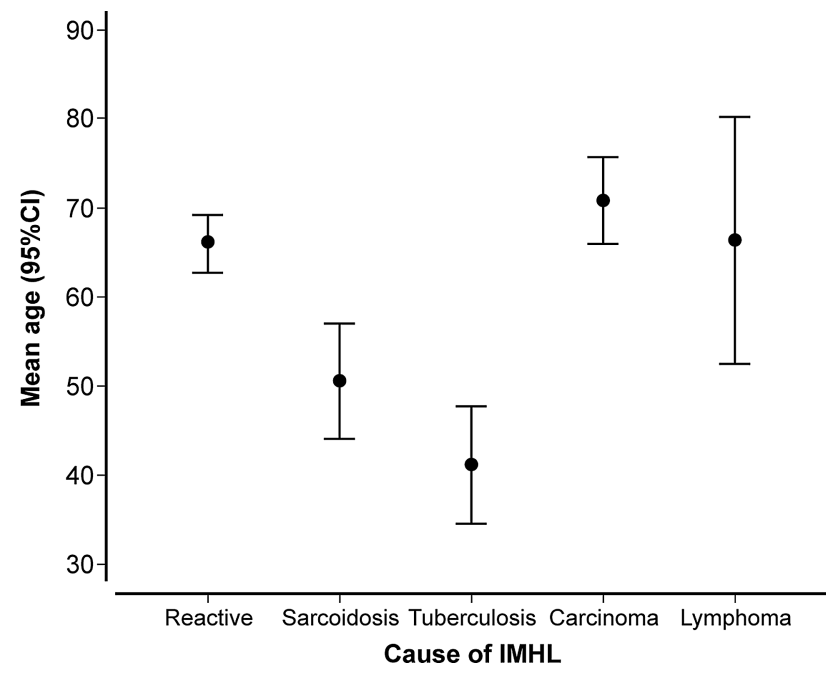

Figure 2 Mean age distribution (years $\pm 95 \% \mathrm{Cl}$ ) stratified according to final diagnosis (IMHL, isolated mediastinal and/or hilar lymphadenopathy).

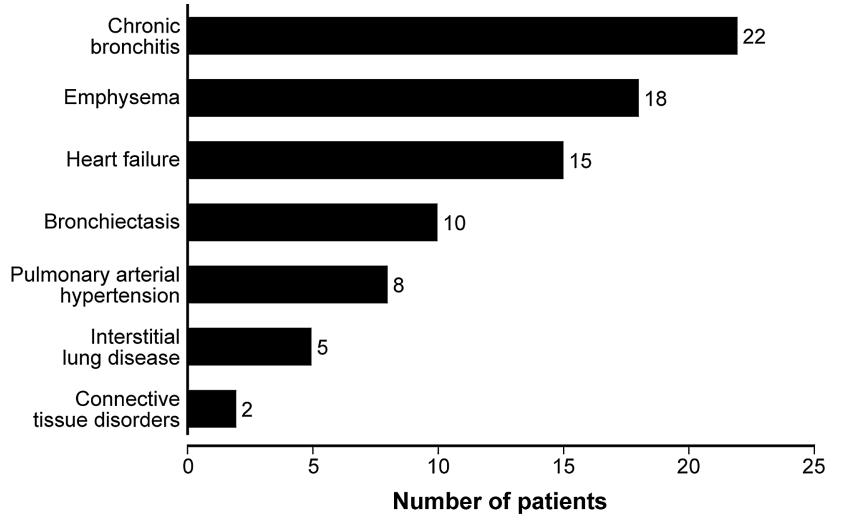

Figure 3 Prevalence of comorbidities associated with isolated mediastinal and/or hilar lymphadenopathy in the study cohort.

likelihood of reactive lymphadenopathy included increasing age (odds ratio (OR) $1.07,95 \%$ CI 1.04 to 1.11 ), white British ethnicity (OR 4.65, 95\% CI 1.76 to 12.26) and the presence of comorbidity (OR 27.86, 95\% CI 9.49 to 81.77); factors associated with a reduced likelihood of a reactive lymphadenopathy were symptoms of weight loss (OR $0.16,95 \%$ CI 0.05 to 0.47 ) and fevers (OR $0.10,95 \%$ CI 0.02 to 0.45 ) and lymph node characteristics including increased numbers of enlarged lymph node stations (OR 0.73 , 95\% CI 0.54 to 0.99 ) and larger lymph node diameter (OR $0.69,95 \%$ CI 0.59 to 0.79 ). Multivariate analysis showed increasing age (OR 1.07, 95\% CI 1.01 to 1.13; $\mathrm{p}=0.033)$ and the presence of at least one relevant comorbidity (OR 9.49, 95\% CI 2.20 to $41.04 ; \mathrm{p}=0.003$ ) to predict for reactive lymphadenopathy and increased maximum lymph node size (OR $0.70,95 \%$ CI 0.59 to 0.83 ; $\mathrm{p}=0.00004)$ to predict pathological IMHL.

Patients were then stratified into a 'low risk' of pathological IMHL, defined as the presence of at least one comorbidity and a maximum lymph node diameter of less than $20 \mathrm{~mm}$, and high risk defined as the absence of comorbidity and a maximum lymph node diameter greater than $20 \mathrm{~mm}$. Age was excluded because patients with malignancy were not of a significantly different age to patients with reactive lymphadenopathy (figure 2). A total of 32 patients were categorised as low risk, which included 30 patients with reactive lymphadenopathy, 1 patient with TB and 1 patient with sarcoidosis. This compared with 68 patients categorised as high risk, which included 50 patients with a pathological cause and 18 patients with a reactive cause of IMHL. The sensitivity and specificity of this model was $96.2 \%$ and $62.5 \%$, respectively. The positive predictive value was $73.5 \%$ and NPV $93.8 \%$ (95\% CI $79.9 \%$ to $98.3 \%$ ).

\section{DISCUSSION}

\section{Summary of main findings}

The cause of IMHL was investigated in 100 consecutive patients referred for EBUS-TBNA at a tertiary UK 
Figure 4 Final diagnosis groups categorised by total number of enlarged lymph node stations.

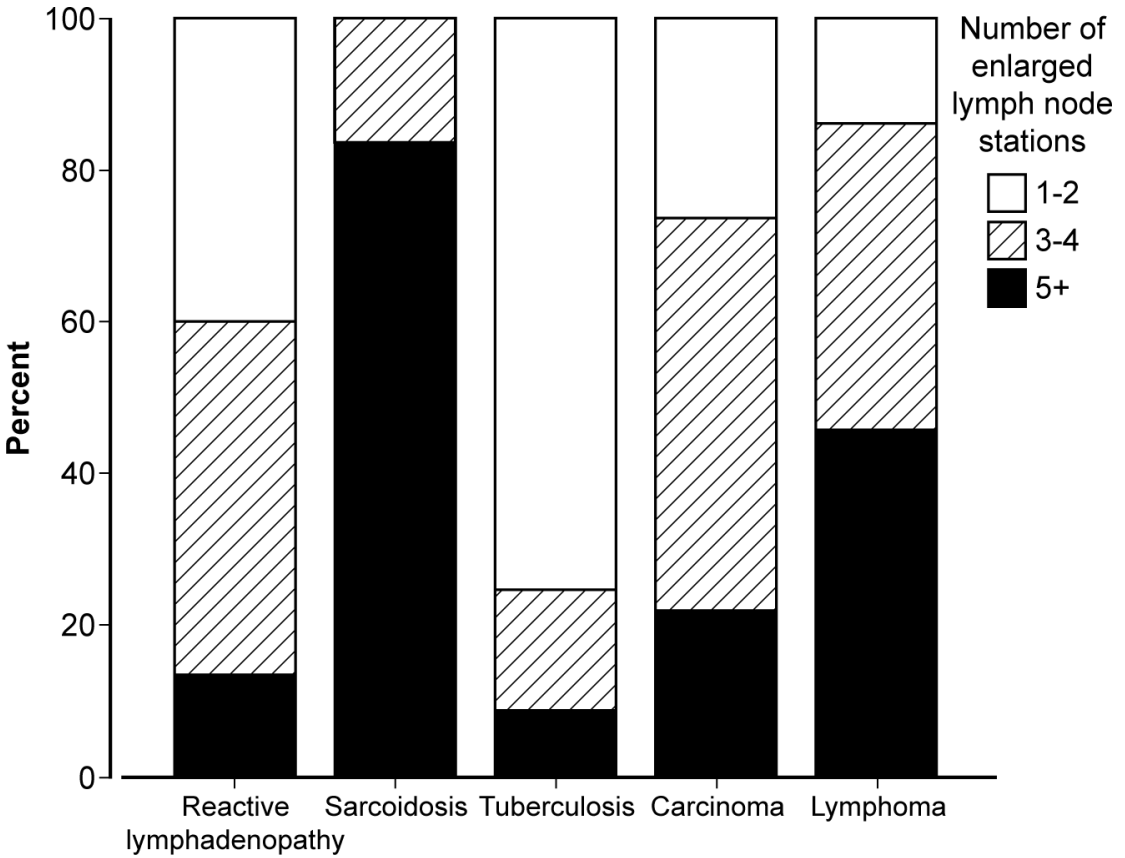

centre. A pathological diagnosis was confirmed in 52 patients, and 48 patients were categorised as having reactive lymphadenopathy $(n=48)$ after repeat sampling or a minimum of 6 months follow-up (mean 16.8 months). EBUS-TBNA correctly diagnosed $91 \%$ of patients with an overall sensitivity of $82.7 \%$ and NPV of $84.2 \%$ (95\% CI $72.6 \%$ to $91.5 \%$ ).

The study also investigated the potential of a number of prospectively recorded patient-related and lymph node-related covariates to differentiate reactive from pathological IMHL. Multivariate analysis showed that age, the presence of comorbidity associated with IMHL and lymph node size to be most discriminating. Lymph node

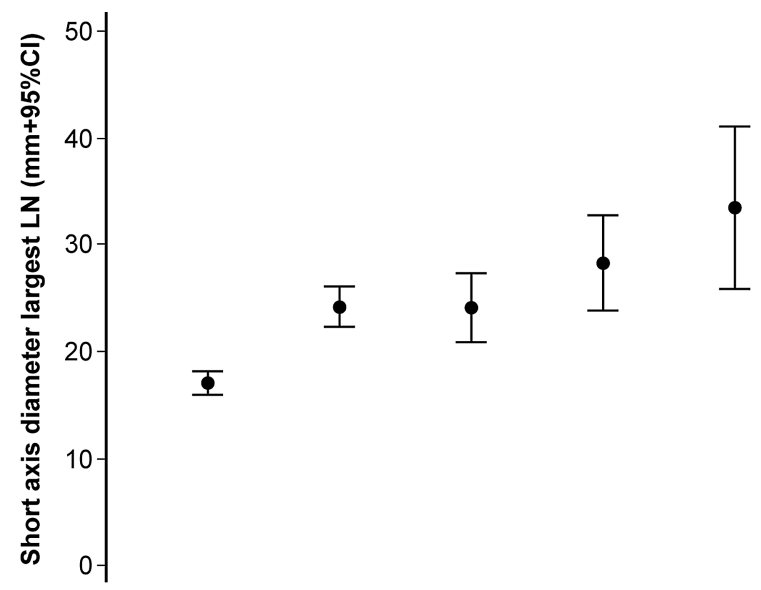

Reactive Sarcoidosis Tuberculosis Carcinoma Lymphoma Cause of IMHL

Figure 5 Mean diameter (short axis) of the largest LN for each patient $(\mathrm{mm} \pm 95 \% \mathrm{Cl})$ stratified according to final diagnosis (IMHL, isolated mediastinal and/or hilar lymphadenopathy). size was the strongest predictor of aetiology, with a maximum lymph node diameter of $15 \mathrm{~mm}$ or less always reactive $(n=16)$ and always pathological when greater than $25 \mathrm{~mm}(\mathrm{n}=25)$. The association of increasing age with reactive IMHL was primarily due to patients diagnosed with granulomatous disorders being significantly younger; no difference in age was seen with patients diagnosed with malignancy. There was a very high prevalence of comorbidities known to be associated with IMHL in patients with reactive lymphadenopathy $(n=39 / 48$, $81.2 \%)$, significantly higher than patients with pathological lymphadenopathy $(\mathrm{n}=7 / 52,13.5 \%$; $\mathrm{p}=<0.000001)$. Indeed, a patient with at least one comorbidity was almost 10 times more likely to have reactive rather than pathological IMHL. This supports the evidence of associations in the published literature and underlines the nature of the lymphadenopathy as 'reacting' to underlying comorbidities. ${ }^{5-12} 17$ The NPV of EBUS-TBNA in low-risk patients, defined as those with a maximum lymph node size less than $20 \mathrm{~mm}$ and having at least one comorbidity, was $93.8 \%$ (95\% CI $79.9 \%$ to $98.3 \%$ ) with only two patients having granulomatous disorders and none having malignancy in this cohort.

\section{Strengths and limitations}

A major strength of this study is the prospective collection of data prior to the diagnosis of IMHL, reducing potential observer bias. All patients referred consecutively for investigation of IMHL were included in the study and successfully underwent sampling. The study population is therefore representative of patients referred with IMHL. How representative this study is of all patients with IMHL is difficult to ascertain. The decision to undertake EBUS-TBNA was at the discretion of the referring physician; the threshold for referral may 
Table 2 Univariate and multivariate analysis of clinical parameters to differentiate between reactive and pathological lymphadenopathy

\begin{tabular}{|c|c|c|c|c|}
\hline Clinical factor & Measure & OR $^{*}$ & $95 \% \mathrm{Cl}$ & p Value \\
\hline \multicolumn{5}{|c|}{ Univariate analysis } \\
\hline Age & Years & 1.07 & 1.04 to 1.11 & 0.00004 \\
\hline Sex & $\mathrm{M}: \mathrm{F}$ & 1.93 & 0.84 to 4.41 & 0.12 \\
\hline Ethnicity & White British vs other & 4.65 & 1.76 to 12.26 & 0.002 \\
\hline \multirow[t]{4}{*}{ Symptoms } & Yes:no & 1.56 & 0.47 to 5.16 & 0.46 \\
\hline & Mean (no) & 0.84 & 0.57 to 1.24 & 0.39 \\
\hline & Weight loss (yes:no) & 0.16 & 0.05 to 0.47 & 0.001 \\
\hline & Fevers (yes:no) & 0.10 & 0.02 to 0.45 & 0.003 \\
\hline Comorbidity & $\geq 1$ (yes:no) & 27.86 & 9.49 to 81.77 & $<0.000001$ \\
\hline \multirow[t]{2}{*}{ Lymph nodes } & Number of stations enlarged & 0.73 & 0.54 to 0.99 & 0.041 \\
\hline & Mean diameter largest & 0.69 & 0.59 to 0.79 & $<0.000001$ \\
\hline \multicolumn{5}{|c|}{ Multivariate analysis } \\
\hline Age & Years & 1.07 & 1.01 to 1.13 & 0.033 \\
\hline Comorbidity & $\geq 1$ (yes:no) & 9.49 & 2.20 to 41.04 & 0.003 \\
\hline Lymph nodes & Mean diameter largest & 0.70 & 0.59 to 0.83 & 0.00004 \\
\hline
\end{tabular}

vary or be related to patient preferences introducing a selection bias.

The study size was not formally calculated but is comparable to the only other prospective study of patients with IMHL. ${ }^{21}$ The primary outcome measure was the NPV of EBUS-TBNA in patients with IMHL (84.2\%, 95\% CI $72.6 \%$ to $91.5 \%$ ). The power of the study is therefore reflected in the $95 \%$ CI of the NPV. Even at the lower end of this CI $(72.6 \%)$, this is significantly greater than the previously reported NPV of $40 \% .^{21}$ Indeed, in low-risk patients, the lower end of the CI was almost double at $79.9 \%$. The diagnosis of reactive IMHL was made after negative EBUS sampling and, in the majority of cases, clinical/radiological follow-up. Only a minority of patients underwent additional sampling, raising the possibility of inaccurate categorisation. However, in the majority of patients, follow-up was for a significantly longer period than 6 months and further sampling was not required in any patient. In the case of TB, lymphoma and carcinoma, it is reasonable to expect progression of lymphadenopathy, without treatment, on serial imaging after a negative EBUS-TBNA. It is unlikely, therefore, that such cases would be inaccurately classified as reactive lymphadenopathy due to a lack of pathological verification, given our long follow-up period in the majority of cases. However, sarcoidosis can regress and remain quiescent, resulting in resolution or stability of lymphadenopathy on serial imaging, even without treatment. Such cases, without further pathological sampling after a negative EBUS-TBNA, would be inaccurately classified as reactive lymphadenopathy in our study. Given that this subgroup of sarcoidosis rarely requires treatment and therefore may not benefit from undergoing further pathological sampling (and the associated risks of mediastinoscopy), it may be reasonable that they are included within a 'low-risk' cohort that could undergo surveillance in the first instance.

\section{Findings in the context of other studies}

The prevalence of reactive lymphadenopathy was $5 \%$ in one previous study of IMHL (REMEDY trial) ${ }^{21}$ compared with $48 \%$ in our study. The REMEDY trial population was younger, more likely to be of non-white British ethnicity and had a larger mean lymph node size, measures all associated with an increased likelihood of pathological IMHL, possibly reflecting differences in patient selection. Patients in the REMEDY trial were selected through specialist multidisciplinary teams, resulting in the sampling of only high-risk individuals; this was not the case in our own study with patients referred at the discretion of local physicians. As a consequence of the difference in the prevalence of reactive IMHL, the NPV of EBUS-TBNA in our study was more than double that previously reported $(84.2 \%$ vs $40 \%){ }^{21}$ This higher NPV, when applied to similar populations in our study, may allow a strategy of surveillance rather than further invasive surgical sampling in cases of IMHL and a negative EBUS-TBNA. This is specifically the case in patients with the presence of comorbidity and maximum lymph node diameter less than $20 \mathrm{~mm}$, as the NPV was even higher at $93.8 \%$.

\section{CONCLUSIONS}

In summary, the population of patients in this study may be a more accurate reflection of the diverse and broad IMHL population that presents to the general respiratory physician in the UK. The prevalence of common comorbidities and the increased availability of CT suggests that IMHL will continue to be a significant burden of work. EBUS-TBNA in this population has a much higher NPV than previous reports suggest. In similar populations, surveillance rather than invasive surgical procedures in carefully selected patients may be appropriate after negative EBUS-TBNA sampling. A multicentre prospective validation of these findings is warranted. 
Contributors ME and RB designed the study. All authors were responsible for data acquisition. ME and PAJC analysed the data and wrote the manuscript. All authors were involved in manuscript revision and approved the final version. $\mathrm{RB}$ is responsible for the overall content as guarantor.

Funding This research received no specific grant from any funding agency in the public, commercial or not-for-profit sectors.

Competing interests RB has received grant funding from Astra-Zeneca and Lilly Oncology and honoraria from Eli-Lilly, AstraZeneca, Chiesi and Almirall. ME's fellowship post is half funded by Lilly Oncology.

Provenance and peer review Not commissioned; externally peer reviewed.

Data sharing statement No additional data are available.

Open Access This is an Open Access article distributed in accordance with the Creative Commons Attribution Non Commercial (CC BY-NC 3.0) license which permits others to distribute, remix, adapt, build upon this work noncommercially, and license their derivative works on different terms, provided the original work is properly cited and the use is non-commercial. See: http:// creativecommons.org/licenses/by-nc/3.0/

\section{REFERENCES}

1. Antao VC, Pinheiro GA, Terra-Filho M, et al. High-resolution CT in silicosis: correlation with radiographic findings and functional impairment. J Comput Assist Tomogr 2005;29:350-6.

2. Talat N, Schulte KM. Castleman's disease: systematic analysis of 416 patients from the literature. Oncologist 2011;16:1316-24.

3. Curtin JJ, Murray JG, Apthorp LA, et al. Mediastinal lymph node enlargement and splenomegaly in primary hypogammaglobulinaemia. Clin Radiol 1995;50:489-91.

4. Wheat LJ, Conces D, Allen SD, et al. Pulmonary histoplasmosis syndromes: recognition, diagnosis, and management. Semin Respir Crit Care Med 2004;25:129-44.

5. Kirchner J, Kirchner EM, Goltz JP, et al. Prevalence of enlarged mediastinal lymph nodes in heavy smokers-a comparative study. Eur Radiol 2011;21:1594-9.

6. Kirchner J, Kirchner EM, Goltz JP, et al. Enlarged hilar and mediastinal lymph nodes in chronic obstructive pulmonary disease. J Med Imaging Radiat Oncol 2010;54:333-8.

7. Bergin C, Castellino RA. Mediastinal lymph node enlargement on CT scans in patients with usual interstitial pneumonitis. AJR Am J Roentgenol 1990;154:251-4.

8. Souza CA, Muller NL, Lee KS, et al. Idiopathic interstitial pneumonias: prevalence of mediastinal lymph node enlargement in 206 patients. AJR Am J Roentgenol 2006;186:995-9.

9. Thomas RD, Blaquiere RM. Reactive mediastinal lymphadenopathy in bronchiectasis assessed by CT. Acta Radiol 1993:34:489-91.

10. Moua T, Levin DL, Carmona EM, et al. Frequency of mediastinal lymphadenopathy in patients with idiopathic pulmonary arterial hypertension. Chest 2013;143:344-8.

11. Chabbert V, Canevet G, Baixas C, et al. Mediastinal lymphadenopathy in congestive heart failure: a sequential CT evaluation with clinical and echocardiographic correlations. Eur Radiol 2004;14:881-9.
12. Pastis NJ Jr, Van Bakel AB, Brand TM, et al. Mediastinal lymphadenopathy in patients undergoing cardiac transplant evaluation. Chest 2011;139:1451-7.

13. Slanetz PJ, Truong M, Shepard JA, et al. Mediastinal lymphadenopathy and hazy mediastinal fat: new CT findings of congestive heart failure. AJR Am J Roentgenol 1998;171:1307-9.

14. Ngom $A$, Dumont $P$, Diot $P$, et al. Benign mediastinal lymphadenopathy in congestive heart failure. Chest 2001;119: 653-6.

15. Erly WK, Borders RJ, Outwater EK, et al. Location, size, and distribution of mediastinal lymph node enlargement in chronic congestive heart failure. J Comput Assist Tomogr 2003;27:485-9.

16. Lewin S, Goldberg L, Dec GW. The spectrum of pulmonary abnormalities on computed chest tomographic imaging in patients with advanced heart failure. Am J Cardiol 2000;86:98-100.

17. Martinez FJ, Karlinsky JB, Gale ME, et al. Intrathoracic lymphadenopathy. A rare manifestation of rheumatoid pulmonary disease. Chest 1990;97:1010-12.

18. Leeds SE, Uhley HN, Sampson JJ, et al. Significance of changes in the pulmonary lymph flow in acute and chronic experimental pulmonary edema. Am J Surg 1967;114:254-8.

19. Leeds SE, Uhley HN, Teleszky LB. Direct cannulation and injection lymphangiography of the canine cardiac and pulmonary efferent mediastinal lymphatics in experimental congestive heart failure. Invest Radiol 1981;16:193-200.

20. Drake RE, Dhother S, Teague RA, et al. Lymph flow in sheep with rapid cardiac ventricular pacing. Am J Physiol 1997;272(5 Pt 2): R1595-8.

21. Navani N, Lawrence DR, Kolvekar S, et al. Endobronchial ultrasound-guided transbronchial needle aspiration prevents mediastinoscopies in the diagnosis of isolated mediastinal lymphadenopathy: a prospective trial. Am J Crit Care 2012;186:255-60.

22. Wong M, Yasufuku K, Nakajima T, et al. Endobronchial ultrasound: new insight for the diagnosis of sarcoidosis. Eur Respir $J$ 2007:29:1182-6.

23. Oki M, Saka H, Kitagawa $\mathrm{C}$, et al. Real-time endobronchial ultrasound-guided transbronchial needle aspiration is useful for diagnosing sarcoidosis. Respirology 2007;12:863-8.

24. Garwood S, Judson MA, Silvestri G, et al. Endobronchial ultrasound for the diagnosis of pulmonary sarcoidosis. Chest 2007;132: 1298-304

25. Navani N, Molyneaux PL, Breen RA, et al. Utility of endobronchial ultrasound-guided transbronchial needle aspiration in patients with tuberculous intrathoracic lymphadenopathy: a multicentre study. Thorax 2011;66:889-93.

26. Dong X, Qu X, Liu Q, et al. Endobronchial ultrasound-guided transbronchial needle aspiration in the mediastinal staging of non-small cell lung cancer: a meta-analysis. Ann Thorac Surg 2013;96:1502-7.

27. Steinfort DP, Conron M, Tsui A, et al. Endobronchial ultrasound-guided transbronchial needle aspiration for the evaluation of suspected lymphoma. J Thorac Oncol 2010;5:804-9.

28. Rusch VW, Asamura $\mathrm{H}$, Watanabe $\mathrm{H}$, et al. The IASLC lung cancer staging project: a proposal for a new international lymph node map in the forthcoming seventh edition of the TNM classification for lung cancer. J Thorac Oncol 2009;4:568-77.

29. Du Rand IA, Blaikley J, Booton R, et al. Summary of the British Thoracic Society guideline for diagnostic flexible bronchoscopy in adults. Thorax 2013;68:786-7. 


\section{Correction}

Evison M, Crosbie PAJ, Morris J, et al. A study of patients with isolated mediastinal and hilar lymphadenopathy undergoing EBUS-TBNA. BMJ Open Resp Res 2014;1:e000040. doi:10.1136/ bmjresp-2014-000040

The heading has changed from 'Respiratory research' to 'Respiratory interventional procedures'.

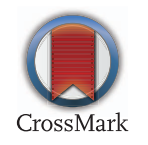

BMJ Open Resp Res 2014;1:e000040corr1. doi:10.1136/bmjresp-2014-000040corr1 